\title{
Clinical role of viral identification by a polymerase chain reaction-based diagnostic panel in adults hospitalized with community-acquired pneumonia
}

\author{
Filippo Lagi ${ }^{1}\left[\right.$ S Simona Pollini ${ }^{1,2} \cdot$ Lorenzo Zammarchi $^{1}$
}

Received: 6 January 2020 / Accepted: 19 January 2020 / Published online: 31 January 2020

(c) Società Italiana di Medicina Interna (SIMI) 2020

Community-acquired pneumonia (CAP) is a significant cause of hospitalization worldwide, and is associated with considerable burden in terms of morbidity and mortality [1].

Although bacteria are a primary cause of CAP, more than 100 microbes including atypical bacteria, viruses, fungi, and parasites, can also cause CAP. The true prevalence of the various etiologic agents remains uncertain, varying from region to region and depending on the laboratory diagnostic capability. CAP epidemiology is changing as a consequence of the widespread introduction of Haemophilus influenzae type $\mathrm{b}$ and pneumococcal vaccines, and the growing role of viruses as cause of CAP is currently a matter of debate [2]. Since neither clinical nor radiological characteristics allow a precise diagnosis, differentiating viral from bacterial pneumonia is challenging and relies upon diagnostic microbiology [3].

New diagnostic tools, based on highly multiplexed polymerase chain reaction (PCR) panels, provide a deeper insight into the possible causes of CAP. In addition to the most frequent Gram-positive and Gram-negative bacteria, the available PCR panels can simultaneously identify multiple respiratory viruses, including rhinovirus, metapneumovirus, adenovirus, coronavirus, respiratory syncytial virus, influenza, and parainfluenza viruses, whose detection could reveal the etiology of many cases in which the identification of a bacterial agent fails [4].

However, these novel assays raised some new questions that need to be addressed. When used on respiratory specimens, including those collected by bronchoscopy, their main

Filippo Lagi

filippo.lagi@unifi.it

1 Department of Experimental and Clinical Medicine, University of Florence, Largo Brambilla 3, 50124 Florence, Italy

2 Microbiology and Virology Unit, Careggi University Hospital, Florence, Italy limitations consist in the qualitative nature of the result and in the possibility of detection of nucleic acids of bacterial and viral contaminants from the upper airway microbiota. It has been reported that about $15 \%$ of healthy persons harbor a respiratory virus at any point in time [5]. This aspect should always be considered during the interpretation of the results, and quantitative or semiquantitative PCR assay, along with clinical data, is necessary to try to override this obstacle.

As contaminants, viruses can be detected as coinfecting agent with bacteria or can pave the way for a subsequent bacterial infection [6]. In this perspective, a large amount of effort is currently being dedicated to elucidate respiratory virus pathogenicity and the interplay between viruses and bacteria.

The recent paper from Tatarelli et al. [7] tried to address in part this gap by analyzing a population of hospitalized patients with CAP in Italy. As acknowledged by the authors, the small sample size and the lack of lower respiratory tract sampling did not allow any firm conclusion to establish a clear causal relationship with lung disease. However, their data confirmed that viral detection is quite a common event, involving about one-third of their study population.

This article, therefore, prompts to reflect about the correct interpretation of viral identification through multiplex PCR assays and how this could positively impact clinical practice, in terms of appropriate therapy prescription, infection control management, and surveillance.

Concerning therapy, in the field of viral CAP, the possibility of effective antiviral therapy is rather limited. In fact, for most respiratory viruses, therapy is mainly supportive, and no specific antiviral is approved. An exception is represented by influenza viruses, whose detection usually indicates a clinical disease, and for which a specific therapy is currently available [6]. In fact, the only medications approved for viral pneumonia in adults are those active against influenza, namely neuraminidase inhibitors. In this scenario, the use of rapid detection methods for influenza 
may help to rapidly decide whether to initiate or discontinue antiviral therapy, and are indicated for every adult patient with suspected or confirmed influenza requiring hospitalization, with or without CAP [8].

Some studies that tried to evaluate the impact of multiplex PCR in terms of antibiotic consumption reduction showed encouraging results, although still not conclusive $[9,10]$. Concerning antibiotic therapy after influenza identification, according to the Infectious Diseases Society of America (IDSA) guidelines, evidence is lacking to define a proper strategy. At the moment, IDSA strongly recommends to start a standard antibacterial therapy for adults with clinical and radiographic evidence of CAP who tested positive for influenza and to re-evaluate after $48-72 \mathrm{~h}$ for an early discontinuation in selected cases [8]. Most clinicians in their daily clinical practice seemed to follow this behavior, as reported in the paper of Tatarelli et al. [7], where days of hospital antibiotic-therapy were similar in viral and bacterial infections. In this context, serum biomarkers such as procalcitonin (PCT), C-reactive protein, and interleukin-6 have been proposed to support clinicians in antibiotic prescription.

However, the majority of the available studies were conducted on children, and results were controversial since these inflammatory markers could also be increased in viral infections, questioning their diagnostic precision and ability to guide antimicrobial therapy $[11,12]$. More evidence is available in favor of PCT, but a recent study concluded that basing decisions exclusively on PCT would result in a proportion of adult patients with bacterial CAP not receiving antibiotics especially those with atypical bacteria [13].

Viral identification remains crucial to set the appropriate infection control measures and for surveillance purposes [14]. Front-line healthcare providers and healthcare facilities should be prepared to evaluate patients for new and emerging infectious diseases such as avian influenza A (e.g. H5N1 and H7N9 viral subtypes) or Middle East Respiratory Syndrome Coronavirus (MERS-CoV). An early detection, a prompt triage, and patient isolation can prevent the spread of the infectious agents in the hospital, or in the country, where the patient is treated [15].

The importance of PCR was very recently highlighted after the alert concerning an outbreak of pneumonia of unknown etiology in China detected in Wuhan City, Hubei Province. The causative agent was promptly identified as a novel betacoronavirus, the 2019 novel coronavirus (2019nCoV) [16]. From December 2019 to January 26, the number of confirmed cases in China climbed up to around 1300 with 41 fatalities and imported case have also been identified in several countries like Thailand, Korea, United states, Taiwan, Japan, Australia, Malaysia, Hong Kong, Macau, Nepal, Vietnam, Singapore and France [17]. Further investigations are still ongoing at the moment.
In conclusion, the exact clinical implications of viral detection by PCR among patients with CAP are still debated. Its role could be strengthened by integrating biomarkers such as procalcitonin to lead to a substantial reduction of unnecessary antibiotic prescriptions and a better outcome for the patients [18]. Finally, even if there is no clear role for the use of specific antivirals to treat viral CAP in adults, apart from influenza, quick viral identification has a major role in infection control management and surveillance.

Funding None.

\section{Compliance with ethical standards}

Conflict of interest The authors declare that they have no conflict of interest.

Statement of human and animal rights This article does not contain any studies with human participants or animals performed by any of the authors.

Informed consent None.

\section{References}

1. Prina E, Ranzani OT, Torres A (2015) Community-acquired pneumonia. Lancet 386:1097-1108. https://doi.org/10.1016/S0140 $-6736(15) 60733-4$

2. Ruuskanen O, Lahti E, Jennings LC, Murdoch DR (2011) Viral pneumonia. Lancet 377:1264-1275. https://doi.org/10.1016/ S0140-6736(10)61459-6

3. Long DA, Long B, Koyfman A (2018) Clinical mimics: an emergency medicine focused review of pneumonia mimics. Intern Emerg Med 13:539-547. https://doi.org/10.1007/s1173 9-018-1840-z

4. Gaydos CA (2013) What Is the role of newer molecular tests in the management of CAP? Infect Dis Clin North Am 27:49-69. https ://doi.org/10.1016/j.idc.2012.11.012

5. Jartti T, Jartti L, Peltola V et al (2008) Identification of respiratory viruses in asymptomatic subjects: asymptomatic respiratory viral infections. Pediatr Infect Dis J 27:1103-1107. https://doi. org/10.1097/INF.0b013e31817e695d

6. Morens DM, Taubenberger JK, Fauci AS (2008) Predominant role of bacterial pneumonia as a cause of death in pandemic influenza: implications for pandemic influenza preparedness. J Infect Dis 198:962-970. https://doi.org/10.1086/591708

7. Tatarelli P, Magnasco L, Borghesi ML et al (2019) Prevalence and clinical impact of viral respiratory tract infections in patients hospitalized for community-acquired pneumonia: the VIRCAP study. Intern Emerg Med. https://doi.org/10.1007/s11739-019-02243-9

8. Metlay JP, Waterer GW, Long AC et al (2019) Diagnosis and treatment of adults with community-acquired pneumonia. Am J Respir Crit Care Med 200:E45-E67. https://doi.org/10.1164/rccm.20190 8-1581ST

9. Qian Y, Ai J, Wu J et al (2019) Rapid detection of respiratory organisms with FilmArray respiratory panel and its impact on clinical decisions in Shanghai, China, 2016-2018. Influenza Other Respir Viruses. https://doi.org/10.1111/irv.12701

10. Mayer LM, Kahlert C, Rassouli F et al (2017) Impact of viral multiplex real-time PCR on management of respiratory tract 
infection: a retrospective cohort study. Pneumonia 9:1-16. https ://doi.org/10.1186/s41479-017-0028-z

11. Bhuiyan MU, Blyth CC, West R et al (2019) Combination of clinical symptoms and blood biomarkers can improve discrimination between bacterial or viral community-acquired pneumonia in children. BMC Pulm Med 19:1-9. https://doi.org/10.1186/s1289 0-019-0835-5

12. Zhou JM, Ye Q (2017) Utility of assessing cytokine levels for the differential diagnosis of pneumonia in a pediatric population. Pediatr Crit Care Med 18:e162-e166. https://doi.org/10.1097/ PCC.0000000000001092

13. Self WH, Balk RA, Grijalva CG et al (2017) Procalcitonin as a marker of etiology in adults hospitalized with communityacquired pneumonia. Clin Infect Dis 65:183-190. https://doi. org/10.1093/cid/cix317

14. Hoellein A, Hecker J, Di H et al (2016) Serious outbreak of human metapneumovirus in patients with hematologic malignancies.
Leuk Lymphoma 57:623-627. https://doi.org/10.3109/10428 194.2015.1067699

15. Dandachi D, Rodriguez-Barradas MC (2018) Viral pneumonia: etiologies and treatment. J Investig Med 66:957-965. https://doi. org/10.1136/jim-2018-000712

16. Huang C, Wang Y, Li X et al (2020) Clinical features of patients infected with 2019 novel coronavirus in Wuhan, China. Lancet. Available from https://www.thelancet.com/journals/lancet/article/ PIIS0140-6736(20)30183-5/fulltext. Accessed 26 Jan 2020

17. ProMED-mail. Available from http://www.promedmail.org/ post/6914553. Accessed 26 Jan 2020

18. Bartoletti M, Antonelli M, Blasi FAB et al (2018) Procalcitoninguided antibiotic therapy: an expert consensus. Clin Chem Lab Med 56:1223-1229. https://doi.org/10.1515/cclm-2018-0259

Publisher's Note Springer Nature remains neutral with regard to jurisdictional claims in published maps and institutional affiliations. 